\title{
Social determinants of household food expenditure in Australia: the role of education, income, geography and time
}

\author{
Danielle Venn, Jane Dixon, Cathy Banwell* and Lyndall Strazdins \\ National Centre for Epidemiology and Population Health, Research School of Population Health, Australian National \\ University, 62 Mills Road, Acton, ACT 0200, Australia
}

Submitted 30 March 2017: Final revision received 9 October 2017: Accepted 13 0ctober 2017: First published online 18 December 2017

\begin{abstract}
Objective: To examine socio-economic status (SES) and time-related factors associated with less healthy food purchases in Australia.

Design: Data were from the 2009/10 Household Expenditure Survey (HES) conducted by the Australian Bureau of Statistics. Regression analysis was used to examine the associations between the proportion of the household food budget spent on various food types (processed and unprocessed foods, foods purchased from takeaways and restaurants) and SES and time constraint variables.

Setting: Australia, 2009-2010.

Subjects: Nationally representative sample of Australian households.

Results: Household income seems to be the most important correlate with food expenditure patterns once other SES indicators are controlled for. Time constraints appear to explain some, but not all, of the adjusted SES gradients in food expenditure. Comparing home food consumption categories (processed and unprocessed foods) with foods purchased away from home (takeaway and restaurant foods) shows that wealthier, more highly educated and least disadvantaged households spend relatively less of their total food budget on processed and unprocessed foods prepared at home and more on foods purchased away from home at restaurants.

Conclusions: Simple SES gradients in dietary behaviour are influenced by correlations between different SES indicators and between SES and time constraints. Examining these factors separately obscures some of the possible causal effects of disadvantage on healthy eating. When formulating policy responses to unhealthy diets, policy makers should consider alternative sources of disadvantage, including time pressure.
\end{abstract}

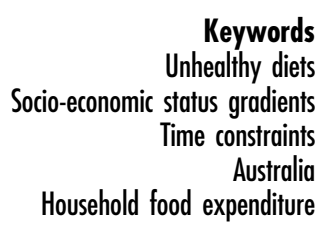

Food purchasing behaviour, diet quality and nutrient intakes vary across groups of differing socio-economic status (SES) in a diversity of countries ${ }^{(1,2)}$. Australian evidence indicates that those from high-SES groups (education, income and occupation), as measured by individual-, household- or community-level indicators, tend to buy and eat healthier foods. Higher levels of education and household income are associated with food purchasing and consumption that adheres more closely to dietary guidelines, including consumption of a wider variety of foods and of more fruits and vegetables ${ }^{(3-9)}$. Those living in low-SES neighbourhoods tend to eat less fruits and vegetables, eat more fast foods and have diets that are higher in fat, salt and sugar, although some of these relationships are attenuated once individual- or household-level characteristics are taken into account. Evidence is still unclear on the relationship between availability of healthy foods in these areas and dietary patterns ${ }^{(7,10,11)}$.
Alternative explanations have been offered for SES (education, income and occupation) variations in diet and other health behaviours. Compared with low-SES groups, high-SES groups may have better health knowledge; greater access to the means to be healthy via financial, social and community capital $^{(1,2,12)}$; greater ability to defer gratification to maintain a healthy weight ${ }^{(13)}$; and greater efficacy in pursuing healthy eating behaviours ${ }^{(1,2)}$. However, isolating the causal effects of SES on diet, and designing appropriate interventions, is made more difficult because SES indicators have been used somewhat interchangeably in the empirical literature ${ }^{(3,12,14)}$. Few studies use multiple indicators of SES and those that do rarely control for different SES indicators simultaneously or in a systematic way. In one of the few Australian studies to do so, Turrell et $a l^{(3)}$ used survey data for Brisbane to find that occupation-based SES gradients in healthy eating are no longer significant once income and education are controlled for. Likewise, education gradients in fruit and vegetable 
purchasing were attenuated by controlling for household income. These studies suggest that an omnibus relationship between SES and diet is not present; instead income, education and occupation and play different, more complex roles.

Another example is time, as a growing body of research is highlighting the importance of time, or lack thereof, as another socially patterned determinant of health behaviours and outcomes ${ }^{(15)}$. Lack of time is commonly reported as a barrier to healthy eating ${ }^{(16-19)}$, while those who report being rushed during meal preparation are less likely to adhere to dietary guidelines ${ }^{(20)}$. Long hours of paid work, a major source of time pressure, are also associated with eating less healthily ${ }^{(21-23)}$.

Time constraints are also highly correlated with SES in Australia, with highly educated people, those living in the wealthiest households or in the least disadvantaged areas most likely to report sometimes or often being rushed for time $^{(24)}$. It is plausible, therefore, that lack of time complicates the SES and diet relationship: at least some of the apparent SES influences on diet could be associated with time constraints rather than income, education or geographical disadvantage per se. However, to our knowledge, no Australian studies have explicitly explored such links.

In the present paper we use a large-scale, nationally representative survey of expenditure in 9725 Australian households to examine the relationship between SES (as measured by education, income and geographical disadvantage) and the proportion of household food budgets allocated to unprocessed and processed foods and foods prepared away from home. Based on existing research on the links between SES and diet reviewed above, we expect that higher-SES households will spend more of their total food budget on healthier foods. The extent to which such SES gradients persist once all three SES variables are controlled for simultaneously will highlight the potential avenues by which SES influences food expenditure decisions. All other things equal, we expect that households facing the tightest time constraints will spend more of their food budget on foods that are quick to prepare, such as pre-prepared meals and other processed foods, or foods prepared away from home.

We advance current research by examining the extent to which unadjusted SES gradients in household food expenditure are attenuated by controlling for multiple SES indicators simultaneously. We expand our analysis to include the extent to which observed SES gradients can be attributed to differences in time constraints, an under-explored social determinant of health. We then discuss the possible health implications of households' food purchasing behaviour.

\section{Methods}

\section{Data source}

We use data from the 2009/10 Household Expenditure Survey (HES) conducted by the Australian Bureau of
Statistics. The survey uses a stratified, multistage cluster design to sample residents of private dwellings in urban and rural areas of Australia (comprising $97 \%$ of the Australian population). Households in very remote areas and those containing foreign diplomatic or military staff were excluded from the scope of the survey. Of those households approached to be part of the survey, $75 \%$ responded with enough information to be included in the final sample.

The survey collects information on household income and expenditure across a range of categories. Data are collected across the Australian fiscal year (1 July to 30 June) so that resulting estimates are representative of expenditure patterns across the fiscal year. Food and nonalcoholic beverage expenditure data are collected using a two-week expenditure diary which is completed by every usual adult household member (aged 15 years or above), with the results aggregated to estimate household-level weekly expenditure. Information on education, income, employment and other personal characteristics is collected using computer-assisted personal interviews with each adult household member, while information on household-level attributes such as household composition is collected in a computer-assisted interview with one adult household member. A household is defined as all those people living within the same dwelling, which may include multi-family (1.8\% of households) or group households (3.2\% of households) ${ }^{(25)}$.

\section{Main variables}

All analysis is done at the household level to reflect the availability of expenditure data and the fact that individuals likely purchase foods and beverages on behalf of other household members. Without further information on the allocation of foods within households, we cannot attribute household food expenditure to individuals. As a result, we also examine explanatory variables at the household level.

\section{Food expenditure (percentage of household budget)}

Food and non-alcoholic beverage expenditure data were recoded into four main summary variables: unprocessed, processed, takeaway and restaurant foods. Processed and unprocessed foods were further disaggregated. The classification used is a variation on that proposed by Monteiro et $a l .{ }^{(26)}$, which classifies food products based on their level of industrial processing. This classification system is attractive for its usefulness in linking food consumption to health effects and has been used in several recent studies of food expenditure and consumption ${ }^{(27-30)}$. Takeaway and restaurant foods were also included as separate categories. While food away from home is not included in Monteiro et al.'s classification system, it comprises an increasingly important share of household food expenditure in Australia $^{(31)}$, accounting for more than one-quarter of total food expenditure on average in the households 
examined. Expenditure in each category is presented in the results as a percentage of total spending on foods and non-alcoholic beverages (Table 1).

A residual category was also included for expenditure that could not be classified into one of the other categories. This primarily includes expenditure that was described in insufficient detail (e.g. 'food') to be classified and accounts for about $4 \%$ of all spending on foods and non-alcoholic beverages. This category is included in overall spending on foods and non-alcoholic beverages but is not used in the analyses in the remainder of the paper.

\section{Age}

All our analyses include a control for the age of the household head because age has been found to influence the relationship between SES, notably education, and diet quality $^{(8)}$. Sensitivity testing using the average age of the household head and spouse (if relevant) did not materially change our results.

\section{Socio-economic status}

Three measures comprise SES. Education is the highest level of educational attainment of either the household head or his/her spouse (whomever has the highest attainment), categorised as follows: did not complete high school; completed high school; vocational qualification; and bachelor degree or higher. We also include a control for the small number of households who are still studying, but these are not shown in the tables because they comprise less than $4 \%$ of the sample.

Household income refers to the quintile of weekly household disposable income (after taxes and transfer payments). It is adjusted for household size using an equivalence scale, modified from the Organisation for Economic Co-operation and Development, that involves dividing total household income by the weighted sum of people in the household, where the first adult is given a weight of 1.0 , a weight of 0.5 is assigned to each subsequent adult and 0.3 for each child ${ }^{(25)}$.

Geographic area disadvantage is defined based on quintiles of the Australian Bureau of Statistics' Index of Relative Socio-Economic Disadvantage. Each household is assigned a quintile based on a range of indicators of the average characteristics of people living in the same geographical area as the household, such as education, occupation, unemployment rate, household income, household composition, Indigenous status and housing tenure $^{(32)}$. The data used in our analysis are based on the national distribution of the index as calculated by the Australian Bureau of Statistics based on detailed geographical information that was collected in the survey, but not released publicly. The index is widely used to measure geographic SES in Australia and previous studies have found that households in disadvantaged areas (defined using this index) tend to have poorer access to supermarkets and greater access to fast foods than those in more advantaged areas ${ }^{(33,34)}$.

We do not include occupation, another SES indicator that is sometimes used in studies of SES gradients in healthy behaviours, because it is available only for those who are employed and is a poor indicator of SES for women $^{(3)}$. The three SES variables used are correlated, but not highly so. The Spearman rank correlation coefficient for each pair is as follows: education-income (0.40); education-geographical disadvantage (0.26); and incomegeographical disadvantage $(0 \cdot 30)$. This suggests that each variable explains at least some unique dimension of SES.

\section{Time constraints}

The HES does not contain a direct measure of time constraints. However, Table 2 shows that our three SES variables are highly correlated with time pressure, as measured in the Australian Time Use Survey. Highly educated people and those living in richer households and less disadvantaged areas are more likely to report being

Table 1 Food classification used in the present study

\begin{tabular}{ll}
\hline Food category & Description \\
\hline $\begin{array}{l}\text { Foods and non-alcoholic beverages } \\
\text { Unprocessed or minimally processed foods and ingredients } \\
\text { Fruits and vegetables }\end{array}$ & Fresh and frozen fruits and vegetables \\
Meat and fish & Fresh and frozen meat and seafood \\
Milk and eggs & Fresh milk, cream and eggs \\
Basic ingredients & Processed ingredients such as rice, pasta, flour, sugar, oils, herbs and spices \\
Tea and coffee & Packaged tea and coffee \\
Processed foods & Processed meat, seafood, fruits, vegetables and dairy products (e.g. cheese, yoghurt), bread, \\
Processed staple foods & breakfast cereal, sauces, spreads and condiments \\
& Sweet and savoury confectionery, cake, biscuits, chocolate and ice cream \\
Snack foods & Canned and packet soup, pre-prepared meals, baby food, canned baked beans and spaghetti \\
Pre-prepared meals & Soft drinks, cordials, fruit juices and bottled water \\
Non-alcoholic beverages & Fast foods and takeaway foods (not frozen) and school lunch money \\
Takeaway foods & Meals in restaurants, hotels, clubs and related \\
Restaurant foods & Foods and beverages that are not described in enough detail to be classified or that cannot be \\
Other foods and beverages & otherwise classified \\
&
\end{tabular}


Table 2 Percentage of Australians aged 15 years or above who always or often feel rushed for time $\mathrm{e}^{(24)}$

\begin{tabular}{|c|c|c|}
\hline & Men & Women \\
\hline \multicolumn{3}{|l|}{ Education } \\
\hline No post-school education & 37 & 40 \\
\hline Vocational qualification & 44 & 49 \\
\hline Tertiary qualification & 52 & 61 \\
\hline \multicolumn{3}{|l|}{ Household income } \\
\hline Poorest $20 \%$ & 27 & 32 \\
\hline Second quintile & 31 & 43 \\
\hline Third quintile & 43 & 47 \\
\hline Fourth quintile & 49 & 51 \\
\hline Richest $20 \%$ & 53 & 59 \\
\hline \multicolumn{3}{|l|}{ Geographical disadvantage } \\
\hline Most disadvantaged area & 36 & 39 \\
\hline Second quintile & 40 & 46 \\
\hline Third quintile & 44 & 49 \\
\hline Fourth quintile & 46 & 48 \\
\hline Least disadvantaged area & 46 & 51 \\
\hline \multicolumn{3}{|l|}{ Paid work hours } \\
\hline Full-time ( $\geq 35 \mathrm{~h} /$ week) & 56 & 65 \\
\hline Part-time $(<35 \mathrm{~h} /$ week $)$ & 40 & 56 \\
\hline Not employed & 18 & 30 \\
\hline \multicolumn{3}{|l|}{ Family situation } \\
\hline Couple without children $<15$ years & 37 & 40 \\
\hline Couple with children $<15$ years & 61 & 67 \\
\hline Lone parent with children $<15$ years & 52 & 61 \\
\hline Lone person & 31 & 29 \\
\hline $\begin{array}{l}\text { Group or multi-family households or adult } \\
\text { children living in family households }\end{array}$ & 41 & 40 \\
\hline
\end{tabular}

rushed for time. This raises the possibility that any SES gradients in food expenditure may be driven, in part, by time constraints.

As we are unable to measure household time constraints directly in the HES, we use two proxies that previous research has found to be correlated with time pressure and time poverty ${ }^{(15)}$. Both are important to include because they capture different sources of time constraints: paid and unpaid work.

Household composition (a series of categories for lone parent or couple family with and without dependent children living at home, plus 'other' households including groups and multiple-family households) is used to proxy time constraints imposed by family responsibilities. Existing research finds that having children or being a lone parent is associated with significantly higher time constraints, even after controlling for other personal and household characteristics ${ }^{(15)}$.

Working time is included to control for time constraints imposed by paid work. Previous studies have found that individuals' eating behaviours can be affected by their own work hours and those of their spouse ${ }^{(23)}$, so we use an indicator of household-level working time to proxy time constraints imposed by paid work. Household paid working time is defined as not working if neither household head nor spouse (if applicable) is working; part-time if either household head or spouse (if applicable) works $1-34 \mathrm{~h} /$ week or one works $\geq 35 \mathrm{~h} /$ week and the other does not work; and full-time if both household head and spouse (if applicable) work $\geq 35 \mathrm{~h} /$ week, otherwise referred to as long working hours.

\section{Analysis}

The paper uses regression analysis to examine the associations between the proportion of the household food budget spent on various food types and SES and time constraint variables. We exclude from our sample thirtythree households who report no weekly expenditure on foods or non-alcoholic beverages, along with sixteen households for whom an indicator of geographic social disadvantage is missing. Our resulting sample size is 9725 households.

Our dependent variable is a proportion, so linear regression is likely to produce biased estimates. Instead, we use a generalised linear model with a logit link function, which constrains the dependent variable to be between 0 and $1^{(35)}$. We first estimate the age-adjusted effects of each SES indicator on food expenditure. We then include the SES measures simultaneously and then with the two time constraint variables added. All analyses were done through the Australian Bureau of Statistics' Remote Access Data Laboratory using the statistical software package Stata version 10, and use the weights provided by the Australian Bureau of Statistics to be representative of the Australian population, but do not control for stratification and clustering because information to do so is not provided in the data set. As a result, our SE may be underestimated. Following Turrell et al. ${ }^{(3)}$, we perform $F$ tests for trend in each of the SES variables, as well as for the joint significance of the time constraint variables. In all but one model, the time constraints were jointly significant at the $95 \%$ level or higher.

\section{Results}

Table 3 shows the association between SES and the proportion of household food expenditure spent on unprocessed, processed, takeaway and restaurant foods. Concentrating on the processed and unprocessed food categories, the results show clear SES gradients in proportional food expenditure when SES variables are included separately. More educated, wealthy and least disadvantaged area households spend a smaller proportion of their total household food budget on processed foods and wealthy households also devote less of their food budget to unprocessed foods.

Simultaneously adjusting for all SES indicators attenuates some of the SES gradients. When income and geographic SES variables are controlled for, higher educated households are associated with allocating a greater proportion of their food budget to unprocessed foods. This suggests that the previous result showing lower spending on unprocessed foods for highly educated households is likely driven by their higher average incomes rather than 
Table 3 Associations between socio-economic status (SES), working time, household composition and food expenditure, expressed as the difference in share of total household food budget spent on each type of food compared with the reference category (percentage points), in a nationally representative sample of Australian households ( $n$ 9725), 2009-2010

\begin{tabular}{|c|c|c|c|c|c|c|c|c|c|c|c|c|}
\hline \multirow[b]{2}{*}{ Adjusted for: } & \multicolumn{3}{|c|}{$\begin{array}{l}\text { Unprocessed foods and } \\
\text { ingredients }\end{array}$} & \multicolumn{3}{|c|}{ Processed foods } & \multicolumn{3}{|c|}{ Takeaway foods } & \multicolumn{3}{|c|}{ Restaurant foods } \\
\hline & $\begin{array}{c}\text { SES } \\
\text { separately }\end{array}$ & $\begin{array}{l}\text { SES } \\
\text { jointly }\end{array}$ & $\begin{array}{l}\text { SES jointly } \\
\quad+\text { time }\end{array}$ & $\begin{array}{l}\text { SES } \\
\text { separately }\end{array}$ & $\begin{array}{l}\text { SES } \\
\text { jointly }\end{array}$ & $\begin{array}{l}\text { SES jointly } \\
\quad+\text { time }\end{array}$ & $\begin{array}{l}\text { SES } \\
\text { separately }\end{array}$ & $\begin{array}{l}\text { SES } \\
\text { jointly }\end{array}$ & $\begin{array}{l}\text { SES jointly } \\
+ \text { time }\end{array}$ & $\begin{array}{c}\text { SES } \\
\text { separately }\end{array}$ & $\begin{array}{c}\text { SES } \\
\text { jointly }\end{array}$ & $\begin{array}{l}\text { SES jointly } \\
\quad+\text { time }\end{array}$ \\
\hline \multicolumn{13}{|c|}{ Education (reference category: Did not finish high school) } \\
\hline High school & -0.3 & 0.7 & 0.5 & $-3 \cdot 2$ & -1.9 & $-2 \cdot 0$ & 1.5 & 0.5 & 0.4 & $5 \cdot 3$ & 3.0 & 3.0 \\
\hline Vocational & -1.4 & $-0 \cdot 1$ & -0.4 & $-2 \cdot 5$ & -0.9 & $-1 \cdot 0$ & 2.0 & 0.6 & 0.6 & 3.9 & 1.5 & 1.7 \\
\hline Tertiary & -0.8 & 1.7 & 1.3 & -7.3 & -3.7 & $-4 \cdot 2$ & 1.1 & $-1 \cdot 2$ & $-1 \cdot 0$ & $10 \cdot 6$ & 4.9 & $5 \cdot 3$ \\
\hline$P$ value for $F$ test of trend & 0.0741 & 0.0082 & 0.0170 & $\begin{array}{l}0.0000 \\
0.19\end{array}$ & 0.0000 & 0.0000 & 0.0022 & 0.0003 & 0.0010 & 0.0000 & 0.0000 & 0.0000 \\
\hline \multicolumn{13}{|c|}{ Household income (reference category: Poorest quintile) } \\
\hline 2nd quintile & -1.7 & -1.8 & $-1 \cdot 3$ & -1.9 & -1.7 & -1.4 & 2.7 & $2 \cdot 6$ & 1.9 & $3 \cdot 2$ & $2 \cdot 8$ & 2.8 \\
\hline 3rd quintile & $-3 \cdot 2$ & -3.5 & $-2 \cdot 6$ & -3.9 & $-3 \cdot 3$ & $-2 \cdot 3$ & 5.8 & 5.8 & 4.2 & 6.2 & $5 \cdot 1$ & 4.7 \\
\hline 4th quintile & -5.5 & -5.9 & -4.7 & -5.8 & -4.8 & -2.9 & $6 \cdot 3$ & 6.5 & $4 \cdot 2$ & $10 \cdot 8$ & 8.8 & 7.6 \\
\hline Richest quintile & -6.4 & $-7 \cdot 2$ & -5.9 & $-11 \cdot 1$ & -9.3 & -6.8 & 7.1 & 7.8 & 5.0 & $17 \cdot 7$ & 13.6 & 11.5 \\
\hline$P$ value for $F$ test of trend & 0.0000 & 0.0000 & 0.0000 & 0.0000 & 0.0000 & 0.0000 & 0.0000 & 0.0000 & 0.0000 & 0.0000 & 0.0000 & 0.0000 \\
\hline Pseudo $R^{2}$ & 0.33 & & & 0.24 & & & 0.38 & & & 0.32 & & \\
\hline \multicolumn{13}{|c|}{ Geographic area disadvantage (reference category: Most disadvantaged area) } \\
\hline 2nd quintile & -0.2 & 0.2 & 0.2 & $-0 \cdot 8$ & $-0 \cdot 0$ & $-0 \cdot 1$ & $1 \cdot 2$ & 0.7 & 0.6 & 1.3 & 0.2 & 0.2 \\
\hline 3rd quintile & -0.7 & 0.2 & 0.2 & $-2 \cdot 2$ & -0.5 & -0.6 & 1.0 & 0.2 & 0.1 & 3.8 & 1.4 & 1.4 \\
\hline 4th quintile & $-1 \cdot 0$ & 0.3 & $0 \cdot 1$ & -3.0 & -0.6 & $-0 \cdot 8$ & 1.4 & $0 \cdot 2$ & 0.4 & 4.9 & 1.3 & 1.5 \\
\hline Least disadvantaged & -1.0 & 0.7 & 0.5 & -5.6 & $-2 \cdot 0$ & -2.5 & 2.0 & 0.5 & 0.7 & 7.9 & 2.5 & 2.8 \\
\hline$P$ value for $F$ test of trend & 0.4592 & 0.8505 & 0.9579 & 0.0000 & 0.0224 & 0.0017 & 0.0168 & 0.8155 & 0.6617 & 0.0000 & 0.0032 & 0.0003 \\
\hline Pseudo $R^{2}$ & 0.30 & 0.32 & & 0.15 & 0.26 & & 0.34 & 0.38 & & $0 \cdot 20$ & 0.34 & \\
\hline \multicolumn{13}{|c|}{ Household paid working time (reference category: Not working) } \\
\hline Part-time & & & -1.8 & & & $-0 \cdot 6$ & & & $2 \cdot 4$ & & & $0 \cdot 2$ \\
\hline \multirow{2}{*}{\multicolumn{13}{|c|}{ Household composition (reference category: Couple without children) }} \\
\hline & & & & & & & & & & & & \\
\hline Lone person & & & -1.2 & & & 0.8 & & & 1.4 & & & -0.7 \\
\hline Couple \& children & & & 0.0 & & & 4.1 & & & $-0 \cdot 3$ & & & -3.6 \\
\hline Lone parent & & & -3.5 & & & 5.0 & & & 1.0 & & & $-4 \cdot 2$ \\
\hline Other & & & $-4 \cdot 1$ & & & $-2 \cdot 4$ & & & 3.7 & & & 0.3 \\
\hline$P$ value for $F$ test of time constraints & & & 0.0000 & & & 0.0000 & & & 0.0000 & & & 0.0000 \\
\hline Pseudo $R^{2}$ & & & 0.34 & & & 0.28 & & & 0.40 & & & 0.36 \\
\hline $\begin{array}{l}\text { Mean \% of household total food and non-alcoholic } \\
\text { beverage budget for sample ( } n \text { 9725) }\end{array}$ & & 29.5 & & & $40 \cdot 4$ & & & 14.4 & & & $12 \cdot 1$ & \\
\hline
\end{tabular}

Marginal effects of independent variables on the share of each food category in the household food budget. Estimates in bold are statistically significant at the $95 \%$ level or higher. For ease of exposition, confidence intervals for marginal effects are not shown in this table but are available from the authors upon request. All regression models include a control for the age of the household head. Pseudo $R^{2}$ shows the correlation between observed expenditure in each category and that predicted by the model. It is a standard measure of goodness-of-fit for generalised linear models of the type used here. 
education per se. Household income continues to exhibit a strong association with food expenditure, even after controlling for other SES variables. The richest households, compared with the poorest households, spend proportionally less of their food budget on unprocessed and processed foods. After controlling for other SES variables, there is no significant geographical gradient in spending on unprocessed foods.

Controlling for time constraints tends to further reduce SES gradients in processed and unprocessed food expenditures, but does not remove them completely. Fulltime household working hours are associated with spending relatively less of the household budget on unprocessed and processed foods. Lone parents spend relatively less of their food budget on unprocessed foods than couples without children, and parents in general spend more on processed foods.

Turning to takeaway and restaurant foods, the results where SES variables are included separately show that low-SES households by all three measures used tend to spend relatively less of their total food budget on restaurant foods than higher-SES households. These relationships are moderated but not completely removed by simultaneously controlling for all three SES variables. The relationship between SES and takeaway foods is less straightforward. Holding income and other SES variables constant, more educated households are associated with allocating a smaller proportion of their food budget on takeaway foods while geographical gradients for takeaway foods are not significant. Full-time households' working hours are associated with spending relatively more of their food budget on takeaway foods than part-time working households. Compared with couples without children, parents spend less eating out at restaurants. Controlling for time constraints reduces somewhat the income and education gradients for relative spending on takeaway foods, but has only a minor impact on the expenditure gradients for restaurant foods.

Generally, comparing home food consumption categories (processed and unprocessed foods) with foods purchased away from home (takeaway and restaurant foods), wealthier, more highly educated and least disadvantaged households spend relatively less of their total food budget on both types of home-prepared foods and more on foods purchased away from home. Household income seems to be the most important correlate with food expenditure patterns once other SES indicators are controlled for. Time constraints appear to explain some, but not all, of the adjusted SES gradients in food expenditure.

Table 4 extends the analysis by examining in detail the share of the food budget allocated to specific types of unprocessed and processed foods, controlling for age, SES and time constraints simultaneously. Highly educated households allocate proportionally more of their food budgets to fruits and vegetables and basic ingredients and less to processed foods than low-educated households, whereas higher-income households are spending proportionally less of their food budget on most kinds of unprocessed and processed staple foods. Households in advantaged areas have reduced spending on milk and eggs and basic ingredients and allocate less of their food budgets to non-alcoholic beverages and pre-prepared meals.

The food budget of households with longer working hours resembles that of households with the highest income: relatively less spending on a range of unprocessed foods compared with non-working households, as well as on processed staple foods. Compared with couples without children, lone parents allocate less of their food budget to fruits and vegetables, meat and basic ingredients, but more to snack foods and pre-prepared meals. A higher proportion of spending on snack foods (as well as on processed staple foods) is also apparent for couples with children, but without a significant drop-off in spending on unprocessed foods. The spending patterns of lone-person households tend to resemble those of loneparent households.

\section{Discussion}

We have examined patterns of food expenditure associated with both SES (income, education and geographical disadvantage) and time constraints (imposed by paid and unpaid work). Generally, we find that people in lower-SES households allocate proportionally more of their food budget to unprocessed and processed foods consumed at home and less to eating out to limit their food expenditure. Our results highlight the importance of considering multiple indicators of SES simultaneously: household income seems to exhibit the most robust relationship with food expenditure, suggesting that it is access to financial resources that plays a stronger role than education/ knowledge or geographical availability of food in decisions about the allocation of the household food budget. The relationships between SES and food expenditure are attenuated somewhat by controlling for time constraints. In particular, households with long working hours tend to exhibit similar expenditure patterns to those with high incomes, suggesting that a lack of time among wealthier households explains part of their expenditure decisions.

Our results can be used to consider how health-related patterns of food expenditure and consumption, and ultimately diet-related health risks, are shaped by household resources. Based on overseas studies by Moubarac et $a l^{(27)}$, Monteiro et $a l^{(26,28)}$ and others ${ }^{(36,37)}$, our assumptions about what expenditure means for health risk can be summarised as a continuum from low-risk unprocessed and minimally processed staple foods through to high-risk, ultra-processed snacks and non-alcoholic beverages (excluding water). In addition, we have 
Table 4 Associations between socio-economic status, working time, household composition and food expenditure, by detailed food category, expressed as the difference in share of total household food budget spent on each type of food compared with the reference category (percentage points), in a nationally representative sample of Australian households ( $n$ 9725), 2009-2010

\begin{tabular}{|c|c|c|c|c|c|c|c|c|}
\hline & \multicolumn{4}{|c|}{ Unprocessed foods and ingredients } & \multicolumn{4}{|c|}{ Processed foods } \\
\hline & $\begin{array}{c}\text { Fruits \& } \\
\text { vegetables }\end{array}$ & $\begin{array}{l}\text { Meat \& } \\
\text { fish }\end{array}$ & $\begin{array}{l}\text { Milk \& } \\
\text { eggs }\end{array}$ & $\begin{array}{c}\text { Basic } \\
\text { ingredients }\end{array}$ & $\begin{array}{l}\text { Processed } \\
\text { staple foods }\end{array}$ & $\begin{array}{l}\text { Snack } \\
\text { foods }\end{array}$ & $\begin{array}{l}\text { Pre- } \\
\text { prepared } \\
\text { meals }\end{array}$ & $\begin{array}{l}\text { Non- } \\
\text { alcoholic } \\
\text { beverages }\end{array}$ \\
\hline \multicolumn{9}{|c|}{ Education (reference category: Did not finish high school) } \\
\hline High school & 0.3 & -0.3 & 0.0 & 0.4 & -0.7 & -0.6 & -0.3 & -0.3 \\
\hline Vocational & -0.1 & -0.4 & 0.2 & -0.1 & -0.5 & -0.2 & -0.3 & 0.1 \\
\hline Degree or higher & 1.2 & -0.5 & $-0 \cdot 1$ & 0.5 & -1.4 & -0.6 & $-1 \cdot 2$ & -0.9 \\
\hline$P$ value for $F$ test of trend & 0.0003 & 0.6306 & 0.6257 & 0.0002 & 0.0263 & 0.2613 & 0.0000 & 0.0000 \\
\hline \multicolumn{9}{|c|}{ Household income (reference category: Poorest quintile) } \\
\hline 2nd quintile & -0.5 & 0.0 & -0.4 & -0.3 & -1.0 & -0.3 & 0.0 & $0 \cdot 1$ \\
\hline 3rd quintile & -0.6 & -0.1 & -0.9 & -0.7 & $-2 \cdot 1$ & -0.5 & 0.1 & 0.3 \\
\hline 4th quintile & -1.5 & -0.3 & $-1 \cdot 3$ & -1.0 & -2.6 & -0.4 & 0.1 & 0.2 \\
\hline Richest quintile & -2.0 & -0.3 & -1.8 & -1.3 & $-4 \cdot 3$ & -1.9 & -0.2 & -0.2 \\
\hline$P$ value for $F$ test of trend & 0.0001 & 0.6950 & 0.0000 & 0.0000 & 0.0000 & 0.0000 & 0.7131 & 0.1531 \\
\hline \multicolumn{9}{|c|}{ Geographic area disadvantage (reference category: Most disadvantaged area) } \\
\hline 2nd quintile & 0.3 & 0.2 & -0.4 & 0.2 & 0.6 & 0.1 & -0.1 & -0.6 \\
\hline 3rd quintile & $1 \cdot 1$ & $-0 \cdot 1$ & -0.6 & 0.1 & 0.2 & -0.1 & 0.1 & -0.8 \\
\hline 4th quintile & 1.1 & -0.2 & -0.8 & 0.2 & 0.1 & 0.1 & -0.1 & -0.8 \\
\hline Least disadvantaged & 1.6 & 0.3 & -1.0 & $-0 \cdot 1$ & -0.3 & -0.4 & -0.5 & $-1 \cdot 1$ \\
\hline$P$ value for $F$ test of trend & 0.0007 & 0.4300 & 0.0000 & 0.4384 & 0.4095 & 0.3433 & 0.0259 & 0.0003 \\
\hline \multicolumn{9}{|c|}{ Household paid working time (reference category: Not working) } \\
\hline Part-time & -0.1 & -0.8 & -0.2 & -0.4 & -1.2 & 0.4 & 0.0 & $0 \cdot 1$ \\
\hline Full-time & -1.0 & -0.6 & -0.7 & -0.6 & $-2 \cdot 0$ & -0.5 & -0.3 & $0 \cdot 1$ \\
\hline \multicolumn{9}{|c|}{ Household composition (reference category: Couple without children) } \\
\hline Lone person & 0.3 & -1.1 & 0.2 & -0.6 & -0.6 & 0.7 & 0.9 & -0.2 \\
\hline Couple \& children & 0.3 & 0.1 & 0.1 & -0.0 & $2 \cdot 0$ & $2 \cdot 0$ & 0.4 & -0.1 \\
\hline Lone parent & $-1 \cdot 1$ & -1.5 & 0.3 & -0.7 & -0.1 & 3.4 & 1.3 & 0.5 \\
\hline Other & -2.0 & -1.7 & -0.0 & -0.2 & -2.6 & -0.3 & $0 \cdot 1$ & 0.4 \\
\hline$P$ value for $F$ test of time constraints & 0.0000 & 0.0002 & 0.0557 & 0.0000 & 0.0000 & 0.0000 & 0.0002 & 0.5677 \\
\hline Pseudo $R^{2}$ & 0.27 & 0.16 & 0.22 & $0 \cdot 17$ & 0.28 & 0.18 & 0.15 & 0.28 \\
\hline $\begin{array}{l}\text { Mean \% of household total food and non- } \\
\text { alcoholic beverage budget for sample } \\
(n 9725)\end{array}$ & 11.9 & $8 \cdot 1$ & 4.6 & $3 \cdot 3$ & 19.9 & $11 \cdot 1$ & 3.9 & $5 \cdot 5$ \\
\hline
\end{tabular}

Marginal effects of independent variables on the share of each food category in the household food budget. All regression models include a control for the age of the household head plus all variables shown in the table simultaneously. Pseudo $R^{2}$ shows the correlation between observed expenditure in each category and that predicted by the model. Estimates in bold are statistically significant at the $95 \%$ level or higher. For ease of exposition, confidence intervals for marginal effects are not shown in this table but are available from the authors upon request.

included takeaway foods, found to be unhealthy due to hidden fats, sugars and salt ${ }^{(38)}$, and restaurant foods, which may be somewhat more healthy ${ }^{(39)}$, although we cannot say where they would fit on the continuum.

Once all three SES indicators are controlled for simultaneously, the implications for health are as diverse as the various combinations among the SES indicators. Household income appears to have the strongest and most consistent effect on relative food expenditure. This accords with previous findings for Australia (as reported, e.g., by Turrell et $a l^{(3,9)}$ ), but the implications for health are somewhat ambiguous. The poorest households spend proportionally more of their food budget on processed (possibly unhealthy) and on unprocessed (probably healthy) foods, and considerably less on foods made away from home, than richer households. When processed and unprocessed foods are examined in further detail, the results suggest more disadvantaged households are spending proportionally less on fruits and vegetables than on other unprocessed foods. More advantaged households are preparing less food at home: they spend proportionally less of their budget on most unprocessed foods, ingredients and processed staples, with little difference in spending on snack foods, pre-prepared meals and beverages. However, they are likely to still spend more on unprocessed foods in total dollar amounts.

At least some of the observed social gradients in income can be attributed to differences in working hours, which may in turn lead to differences in time constraints. Household full-time work is associated with relatively lower expenditure on healthy foods. There is a lower proportion of food budgets allocated to buying unprocessed foods (and also processed foods), which is offset by higher spending on takeaway foods. High-income households tend to have long working hours, so once working hours are controlled for, some of the income effect disappears. Thus, in these households, eating out reflects long working hours more than high income. Like the richest people, those with long work hours are spending relatively less of their budget on foods to prepare at home; instead they are investing more of their food budget in pre-prepared meals and dining out, presumably 
to save time and effort. Some studies have not found a relationship between time poverty and poorer diet quality $^{(40,41)}$; the first focuses specifically on fast foods and the second uses a small sample of women only, making both more limited in scope than ours.

The households with greatest time constraints (lone parents) have the least healthy food expenditure patterns: less unprocessed foods, more processed foods, more takeaway foods. The extent to which this is due to time constraints alone is difficult to ascertain; in some ways they resemble couples with children (who are also likely to be time poor), but also lone-person households (who are less likely to be time poor), so perhaps the use of foods prepared outside the home reflects a desire for convenience over cooking rather than time constraints per se. The results for lone parents, where processed snack foods and meals are substituted for fresh foods in food budget allocation, may be related to the relative cheapness of processed foods. Qualitative studies among lower-SES households offer additional reasons for this finding: rather than 'wasting' money on fruits and vegetables that may be thrown out, processed foods are purchased because children will eat them readily ${ }^{(42)}$; while foods that provide children with nutri-tainment ${ }^{(43)}$, i.e. mainly highly marketed processed foods and meals, are popular.

After taking account of age and other SES indicators, education seems to be associated with healthier and more expensive purchasing allocations. Compared with the least educated, highly educated households spend relatively more on fruits and vegetables and basic ingredients, and relatively less on most types of processed foods, while their eating away from home is skewed towards restaurant, rather than takeaway, foods. Reflecting on food categories in Table 3 suggests that the expenditure strategies for disadvantaged groups are a response to the fact that unprocessed foods are comparatively expensive and time consuming to prepare compared with processed foods, while takeaway meals compared with restaurants foods are quicker to purchase and comparatively inexpensive. The dietary patterns of disadvantaged groups could be seen as strategies to save both time and money in the context of limited resources.

Similar to other Australian studies ${ }^{(10,44)}$, we find that geographical factors are less important than householdlevel factors in explaining food expenditure. Once other SES indicators are controlled for, we see that households in the least disadvantaged areas spend proportionally less on processed foods - notably pre-prepared meals and beverages - and more on restaurant foods than those in the most disadvantaged areas. They also spend significantly more on fruits and vegetables. Unlike Thornton et $a l^{(10)}$, we do not find that spending on takeaway foods is higher in disadvantaged areas, although we are not able to assess the frequency of takeaway purchases.

The analysis reported here is limited in several ways. Total food expenditure is a combination of quantity and price, but it is not possible to determine the relative importance of each. For example, higher spending on particular food items may reflect greater quantity or higher-priced options (e.g. branded $v$. unbranded products). Even if purchased quantities were known, this would still not be a perfect proxy for consumption and more direct measures of healthy eating behaviours are needed. Our unit of analysis is the household and it is unlikely that consumption, SES and time constraints are evenly distributed across household members. While the inclusion of takeaway and restaurant meals is a valuable addition to analyses of dietary patterns, their respective nutritional values cannot be taken for granted given the diversity of foods on offer within both categories. In addition, the analysis would have benefited from direct controls for both time pressure and time poverty. Nevertheless, the analysis provides some indication that temporal factors can mediate SES gradients in food expenditure.

\section{Conclusion}

The current analysis highlights that SES gradients analysed separately obscure some of the possible causal effects of disadvantage on healthy eating. The SES indicators examined in the present paper are not associated with dietary behaviours in the same way and some of the unadjusted SES gradients in food expenditure are the result of confounding by other indicators. SES is also highly correlated with time constraints, with those in the most advantaged groups typically reporting higher rates of time pressure. Controlling for time constraints attenuates some of the observed relationships between SES and food expenditure, providing further evidence that time is an important resource for health.

Our results imply that when considering responses to unhealthy diets, policy makers need to be aware that by focusing on isolated SES indicators they can identify only individual and specific dietary health risks, making single indicator-based responses less than effective. Instead, they should consider multiple sources of disadvantage when considering policy options.

The importance of household education level, for example, could lead to arguments for more nutrition education among those with lesser educational qualifications. However, research suggests that lower-SES groups know the basics of 'good' nutrition ${ }^{(45)}$ but they do not necessarily adopt it in the same way as higher-SES groups ${ }^{(42,46)}$. It is possible that the highly educated prioritise health implications of expenditure decisions because they have psychosocial and economic incentives in terms of occupational mobility and earnings capacity ${ }^{(13)}$. In terms of temporal constraints on dietary patterns, plausible policy responses depend on the socio-economic characteristics of the group in question ${ }^{(17)}$. For the employed, 
overly long working hours are contributing to less healthy diets although working hours are a contested target among industrial relations protagonists. For those outside the labour market who are time constrained, the response may lie in access to food environments which provide healthy convenience foods.

Finally, the type of analysis conducted here is confined to routinely measured SES indicators and cannot readily incorporate insights gained from qualitative studies regarding the sociocultural factors that influence dietary choices. These include food's role in pleasure, family harmony and social group identity, as well as non-economic assessments of health risks which are influenced by perceptions of the importance of health behaviours $^{(47)}$ and attitudes towards healthy nutrition ${ }^{(48)}$.

There are growing calls to realign public health research focus away from individual behaviours to an understanding how behaviours are modified by daily schedules and routines ${ }^{(49)}$, household dynamics ${ }^{(50)}$, accepted ways of living ${ }^{(51)}$ and time use ${ }^{(17)}$. Such a move towards social practices research, which emphasises interactions of macro-policy levers relating to education, employment and urban planning with meso-level ways of living, could inform a range of public health strategies. For example, should governments limit the appeal of nutritionally inferior foods through curbing food marketing and promotions, promote positive healthy food-related themes, or participate in the reframing of narratives around consumption-oriented lifestyles and well-being which consider healthy nutrition to be the outcome of a multilevel system?

\section{Acknowledgements}

Financial support: This work was supported by the Australian Research Council of Australia (ARC) Discovery Project (DP1400102856). The ARC had no role in the design, analysis or writing of this article. Conflict of interest: None. Authorship: D.V. analysed the quantitative data while C.B., J.D. and L.S. provided sociological insights on food trends. All authors wrote the article and provided references. Ethics of human subject participation: Not applicable.

\section{References}

1. Darmon N \& Drewnowski A (2008) Does social class predict diet quality? Am J Clin Nutr 87, 1107-1117.

2. Pampel FC, Krueger PM \& Denney JT (2010) Socioeconomic disparities in health behaviors. Annu Rev Sociol 36, 349-370.

3. Turrell G, Hewitt B, Patterson C et al. (2003) Measuring socio-economic position in dietary research: is choice of socio-economic indicator important? Public Health Nutr $\mathbf{6}$, 191-200.

4. Worsley A, Blasche R, Ball K et al. (2004) The relationship between education and food consumption in the 1995
Australian National Nutrition Survey. Public Health Nutr 7 , 649-663.

5. Worsley A, Blasche R, Ball K et al. (2003) Income differences in food consumption in the 1995 Australian National Nutrition Survey. Eur J Clin Nutr 57, 1198-1211.

6. Ball K, Crawford D \& Mishra G (2006) Socio-economic inequalities in women's fruit and vegetable intakes: a multilevel study of individual, social and environmental mediators. Public Health Nutr 9, 623-630.

7. McNaughton SA, Ball K, Crawford D et al. (2008) An index of diet and eating patterns is a valid measure of diet quality in an Australian Population. J Nutr 138, 86-93.

8. Backholer K, Spencer E, Gearon E et al. (2016) The association between socio-economic position and diet quality in Australian adults. Public Health Nutr 19, 477-485.

9. Turrell G, Hewitt B, Patterson C et al. (2002) Socioeconomic differences in food purchasing behaviour and suggested implications for diet-related health promotion. J Hum Nutr Diet 15, 355-364.

10. Thornton LE, Crawford DA \& Ball K (2010) Neighbourhoodsocioeconomic variation in women's diet: the role of nutrition environments. Eur J Clin Nutr 64, 1423-1432.

11. Turrell G, Bentley R, Thomas LR et al. (2009) A multilevel study of area socio-economic status and food purchasing behaviour. Public Health Nutr 12, 2074-2083.

12. Turrell G \& Vandevijvere S (2015) Socio-economic inequalities in diet and body weight: evidence, causes and intervention options. Public Health Nutr 18, 759-763.

13. Offer A (1998) Epidemics of Abundance: Overeating and Slimming in the USA and Britain Since the 1950s. Discussion Papers in Economic and Social History no. W25. Oxford: Department of Economics, Oxford University.

14. Braveman PA, Cubbin C, Egerter S et al. (2005) Socioeconomic status in health research: one size does not fit all. JAMA 294, 2879-2888.

15. Strazdins L, Welsh J, Korda R et al. (2016) Not all hours are equal: could time be a social determinant of health? Sociol Health Illn 38, 21-42.

16. Welch N, McNaughton SA, Hunter W et al. (2009) Is the perception of time pressure a barrier to healthy eating and physical activity among women? Public Health Nutr 12, 888-895.

17. Inglis V, Ball K \& Crawford D (2005) Why do women of low socioeconomic status have poorer dietary behaviours than women of higher socioeconomic status? A qualitative exploration. Appetite 45, 334-343.

18. Banwell C, Hinde S, Dixon J et al. (2005) Reflections on expert consensus: a case study of the social trends contributing to obesity. Eur J Public Health 15, 564-568.

19. Jabs J \& Devine CM (2006) Time scarcity and food choices: an overview. Appetite 47, 196-204.

20. Mothersbaugh DL, Herrmann RO \& Warland RH (1993) Perceived time pressure and recommended dietary practices: the moderating effect of knowledge of nutrition. J Consum Aff 27, 106-126.

21. Bauer KW, Hearst MO, Escoto K et al. (2012) Parental employment and work-family stress: associations with family food environments. Soc Sci Med 75, 496-504.

22. Datar A, Nicosia N \& Shier V (2014) Maternal work and children's diet, activity, and obesity. Soc Sci Med 107, 196-204.

23. Fan W, Lam J, Moen P et al. (2015) Constrained choices? Linking employees' and spouses' work time to health behaviors. Soc Sci Med 126, 99-109.

24. Australian Bureau of Statistics (2006) How Australians Use Their Time. Catalogue no. 4153.0. Canberra: ABS.

25. Australian Bureau of Statistics (2012) Household Expenditure Survey and Survey of Income and Housing, User Guide, Australia 2009-10. Canberra: ABS. 
26. Monteiro CA, Levy RB, Claro RM et al. (2010) A new classification of foods based on the extent and purpose of their processing. Cad Saude Publica 26, 2039-2049.

27. Moubarac J-C, Martins APB, Claro RM et al. (2013) Consumption of ultra-processed foods and likely impact on human health. Evidence from Canada. Public Health Nutr 16, 2240-2248.

28. Monteiro CA, Levy RB, Claro RM et al. (2011) Increasing consumption of ultra-processed foods and likely impact on human health: evidence from Brazil. Public Health Nutr 14, 5-13.

29. Juul F \& Hemmingsson E (2015) Trends in consumption of ultra-processed foods and obesity in Sweden between 1960 and 2010. Public Health Nutr 18, 3096-3107.

30. Smith C, Gray AR, Mainvil LA et al. (2015) Secular changes in intakes of foods among New Zealand adults from 1997 to 2008/09. Public Health Nutr 18, 3249-3259.

31. Venn D, Banwell C \& Dixon J (2017) Australia's evolving food practices: a risky mix of continuity and change. Public Health Nutr 20, 2549-2558.

32. Adhikari P (2006) Socio-Economic Indexes for Areas: Introduction, Use and Future Directions. Canberra: ABS.

33. Burns CM \& Inglis AD (2007) Measuring food access in Melbourne: access to healthy and fast foods by car, bus and foot in an urban municipality in Melbourne. Health Place 13, 877-885.

34. Thornton LE, Lamb KE \& Ball K (2016) Fast food restaurant locations according to socioeconomic disadvantage, urbanregional locality, and schools within Victoria, Australia. SSM Popul Health 2, 1-9.

35. Baum C (2008) Modeling proportions. Stata J 8, 299-303.

36. Canella DS, Levy RB, Martins APB et al. (2014) Ultraprocessed food products and obesity in Brazilian households (2008-2009). PLoS One 9, e92752.

37. Mozaffarian D, Hao T, Rim E et al. (2011) Changes in diet and lifestyle and long-term weight gain in women and men. N Engl J Med 364, 2392-2404.

38. Pereira MA, Kartashov AI, Ebbeling CB et al. (2005) Fast-food habits, weight gain, and insulin resistance (the CARDIA study): 15-year prospective analysis. Lancet 365, 36-42.

39. Duffey K, Gordon-Larsen P, Jacobs D Jr et al. (2007) Differential associations of fast food and restaurant food consumption with $3-y$ change in body mass index: the
Coronary Artery Risk Development in Young Adults Study. Am J Clin Nutr 85, 201-208.

40. Kalenkoski CM \& Hamrick KS (2012) How does time poverty affect behavior? A look at eating and physical activity. Appl Econ Perspect Policy 35, 89-105.

41. Miller J, Chan L, Mehta K et al. (2016) Dietary intake of working women with children does not appear to be influenced by hours of employment: a secondary analysis of the Australian Health Survey (2011-2013). Appetite 105, 106-113.

42. Dixon J \& Isaacs B (2013) Why sustainable and 'nutritionally correct' foods are not on the local agenda: Western Sydney, the moral arts of everyday life and public policy. Food Policy 43, 67-76.

43. Wilk R (2012) Eating as Moral Philosophy. Invited Lecture, Program in Food Studies. London: SOAS University of London.

44. Turrell G \& Giskes K (2008) Socioeconomic disadvantage and the purchase of takeaway food: a multilevel analysis. Appetite 51, 69-81.

45. Hendrie G, Coveney J \& Cox D (2008) Exploring nutrition knowledge and the demographic variation in knowledge levels in an Australian community sample. Public Health Nutr 11, 1365-1371.

46. Warin M, Turner K, Moore D et al. (2007) Bodies, mothers and identities: rethinking obesity and the BMI. Sociol Health Illn 30, 97-111.

47. Wang W, Worsley A \& Cunningham E (2008) Social ideological influences on reported food consumption and BMI. Int J Behav Nutr Phys Act 5, 20.

48. Aggarwal A, Monsivais P, Cook A et al. (2014) Positive attitude toward healthy eating predicts higher diet quality at all cost levels of supermarkets. J Acad Nutr Diet 114, 266-272.

49. Jastran MB, Sobal J, Blake C et al. (2009) Eating routines: embedded, value based, modifiable, and reflective. Appetite 52, $127-136$.

50. Schubert L (2008) Household food strategies and the reframing of ways of understanding dietary practices. Ecol Food Nutr 47, 254-279.

51. Blue S, Shove E, Carmona C et al. (2016) Theories of practice and public health: understanding (un)healthy practices. Crit Public Health 26, 36-50. 